\title{
CHANGING SOCIAL ATTITUDES TOWARDS LGBT IN VIETNAM
}

\author{
Quan Thuong Pham \\ Vietnam national university - Ho Chi Minh city
}

February, 2022

\begin{abstract}
This paper attempts to characterize the transformation of social attitudes towards the lesbian, gay, bisexual, and transgender (LGBT) community in Vietnam over the past decade since the establishment of civil society organizations in the late 2000s. With substantial rise in LGBT representation in media, I take advantage of media sources to point out the causes of social attitudes change towards the LGBT community in Vietnam over the past decade, characterized by the interplay of social activism, political change and media effect. This paper finds that social attitudes on LGBT issues in the last decade have been changing in a more positive and open direction to this community, manifesting the normalization of homosexuality. However, heteronormativity still exists in parallel with the normalization of homosexuality in Vietnam.
\end{abstract}

Key words: homosexuality, social attitudes towards LGBT, normalization of homosexuality, heteronormativity, Vietnam.

\section{INTRODUCTION}

Research on social attitudes towards LGBT (SATL) is attracting increasing interest from researchers in a rapidly changing social context for homosexuality (Adamczyk \& Liao, 2019). Although the research on this issue is diverse in different countries and cultures, there is generally more openness globally (Inglehart \& Welzel, 2005; Smith et al., 2014). Many nations around the world have undergone shifts in how their societies view LGBTQ-related issues, 
increased media coverage, and changes to related laws and policies (Adamczyk \& Cheng, 2015; Andersen \& Fetner, 2008; Hadler, 2012; Lewis \& Gossett, 2008). However, in Confucian countries, mostly in East Asia, there is still controversy about this movement's progress. Zheng (2015) argues the idea that Chinese society is more open to LGBT is not convincing due to widespread negative attitudes and discrimination in the country. For the Vietnamese context, there is rare academic research directly addressing this issue apart from some partly related studies and reports with more attention on the negative aspects of the issue (Horton, 2019; Oosterhoff et al., 2014; Zheng, 2015). In addition, newspaper articles and interviews with social activists also put more weight on stigma and discrimination in Vietnam (Hodal, 2020; Lewis, 2016; Mosbergen, 2015; Nguyen, 2020). However, there are also bright looks on this issue in Vietnam, considering this is the top open country for LGBT (Maresca, 2013; Winn, 2015). In these Confucian countries, there are still few academic studies on SATL (Adamczyk, 2017). These controversies, lack of research and conflicting opinions have led to an urgent demand for a more up-to-date, objective study on SATL in Vietnam. This study is conducted for that demand to investigate the cause and characteristic of changing SATL in Vietnam.

This research provides some radical understandings on the SATL in Vietnam. First, the cause of SATL transformation in Vietnam comes from social movement, political change and media movement in the world and especially in Vietnam during the last decade. In the late 2000s and early 2010s, social activism played a central role in initiating, advocating for equal rights including same-sex marriage and combating discrimination. It is social activism with some achievements in politics and society that has aroused media and in the late 2010s and early 2020s so that in this period, media plays a prominent role in conveying LGBT information, images, stories and thereby has a great impact on social attitudes. Second, with the mentioned impacts, the SATL in Vietnam has experienced a positive change in all aspects of affection, 
behavior and cognition among various social classes and demographic group. Third, despite more openness for LGBT in Vietnam, heteronormativity still exists in parallel with the normalization of homosexuality.

\section{GAY RIGHT MOVEMENT AND SOCIAL ATTITUDES TOWARDS LGBT (SATL) ACROSS CULTURES}

The earliest signs of gay rights movement dated back to the early 20th century since the establishment of some initial organizations fighting for LGBT rights (CNN, 2019). Since then, the campaign to advocate for the rights of LGBT people has developed and spread with many goals and forms. In the early 1950s was an activity such as homophile movement focusing on self-help and self-acceptance. During the next two decades, liberation progress was promoted to claim LGBT's freedom. Since the 2000s, this movement is raised up to demand equal rights for LGBT such as marriage and child-rearing. Social equality is usually deployed as the utmost purpose for this movement, but denial of full LGBT rights still widespread in the world (Rhoades, 2011). Today, there is a wide range of social and political activism such as lobbying, marches on the street, social groups, education and training, research, media and art. Although the LGBT movement has been taking place extensively and effectively in many countries, in other parts of the world, this movement still faces barriers from politics, religion, culture and society (Adamczyk, 2017; Gould \& Moe, 2015).

The development of the LGBT movement in the past century has been associated with the change of SATL. Globally, this kind of social awareness changes in a positive direction that is more and more tolerant and supportive for LGBT. Referring to World Values Survey (WVS), Inglehart and Welzel (2005) conclude judgments that homosexuality was "never justified" decreased in 42 out of 51 countries. Smith et al. (2014), using the International Social Survey 
Program (ISSP), also states that the global trend is towards greater approval of homosexuality with $87 \%$ of countries moving in that direction and with the gains in approval also being larger than the declines. However, many studies in various contexts report that stigma and discrimination are still widespread (Hutt, 2018; Smith et al., 2014). As mentioned, there has been controversy about the nature and direction of this process among Confucian countries like China and Vietnam (Newton, 2014; Zheng, 2015). This contradiction may raise confusion or disappointment about the LGBT advocacy progress in these contexts. In addition, although a lot of research on the factors that shape cross-national attitudes has been conducted so far, most of the work concentrates on attitudes of the Western world and among monotheistic religion countries (i.e., Christianity and Islam) (Akker et al., 2012; Scheepers et al., 2002). Very little research pays attention to factors that impact SATL in Confucian nations in East Asia with cultural influence from China (Adamczyk, 2017). The contrasting perspectives and lack of research are the triggers for this research in Vietnam.

\section{SATL IN VIETNAM}

Some of the world's views about Vietnam recognize this country as an open and advanced environment for LGBT (Mosbergen, 2015; Winn, 2015). However, up to now, there are still conflicting opinions about the process of social attitude towards LGBT in Vietnam. Although international organizations, civil society organizations and LGBT activists still acknowledge some achievements in politics and society, they still affirm that prejudice and discrimination are still prevalent in Vietnam (Do et al., 2019; Luong \& Pham, 2015; UNDP \& USAID, 2014). Some academic studies of domestic and foreign authors have expressed agreement with the above point of view that the heteronormativity origin and the marriage regime stem from Confucian ideology leading to the fact that stigma and discriminatory treatment are still widespread across many areas of life and are still deeply embedded in the thought of society 
and the Vietnamese government (Adamczyk \& Cheng, 2015; Horton, 2019; Newton, 2015; Oosterhoff et al., 2014). Why is there this contradiction and whether the advocacy for LGBT rights in the world and in Vietnam have not brought enough achievement for the change in SATL in Vietnam? It is these concerns that have led to the research need to promptly update the changing situation of SATL in Vietnam, thereby serving as the basis for theoretical and practical activities on LGBT rights and social development in Vietnam, as well as providing more evidence and experience to other contexts.

To solve this problem, I concretize into three research questions. Firstly, what are the causes of the changing movement of SATL in VN? Second, what are the nature, characteristics and direction of this movement over the past decade? Last, how do the process of homosexual normalization and heteronormativity circulate at the same place?

\section{METHOD}

Research on SATL is mainly done by survey with a substantial cost and potential bias, while information sources from media are increasing with opportunities to provide the depth of data (Adamczyk \& Liao, 2019). Sender (2006) notes that since 2000 there has been a significant change in LGBT representation in both mainstream media and self-representation thanks to advancements in technology and media genres. This is similar to that in Vietnam, especially after the Vietnamese government abolished the law banning same-sex marriage in 2014. Social movement, positive political changes related to sexual orientation are the main drivers for that media process. I will analyze these drivers in the "finding" part. In this paper, although media is the primary source of data collection, it will also be discussed as a cause of SATL change in Vietnam. The simple reason is that media both reflects and influences society. The cited newspapers and magazines are leading prestigious newspapers in Vietnam, such as Tuoitre.vn, Thanhnien.vn, VNexpress.net and in the world such as Time, Bloomberg, The Atlantic, NBC 
news ... Visual information is also referred from channels and television programs of leading public speech agencies in Vietnam such as VTV (Vietnamese television), HTV (Ho Chi Minh city television), ANTV (People's police television), THVL (Vinh Long province television) ) and the channels or programs on YouTube of the above-mentioned speech agencies or private, professional organizations (e.g., MCV media) and other non-professional individuals and organizations to provide an objective and comprehensive view for research. Other sources of secondary information collection in this research article are statistics, research and reports from individuals and organizations. Reports and studies on LGBT issues in Vietnam are obtained from international organizations such as USAID, UNDP, civil society organizations working for LGBT rights such as ICS, ISEE and other domestic and foreign individuals.

When studying social attitudes, we cannot help mentioning the definition and aspects of this phenomenon. Attitude is a psychological construct, a settled way of thinking or feeling about something (Perloff, 2017). Major topics in the study of attitude are attitude-behavior relationships, attitude change, attitude strength, consumer behavior. Although there have been attempts to build measurements for this construct in quantitative studies, the need for depth and detail of the information should be achieved through qualitative research (Flores, 2015), especially timely exploitation of new online media (Adamczyk \& Liao, 2019; Pullen \& Cooper, 2010). That is also the methodological approach of this research. Due to the qualitative research being inductive, I focused on data to build the themes. I do not adopt quantitative research measurements on SATL but instead use a generalized model of attitude to make it easier to arrange and systemize the themes of SATL in Vietnam. Breckler (1984) suggests a prominent multicomponent model for scrutinizing attitude in terms of affect, behavior and cognition (ABC model). The "Affective" component refers to our feelings or emotions towards an object. "Behavioral" component is manifested in the way we act and behave to something 
or someone, and "Cognitive" component are the thoughts, beliefs and attributes that we have on a target. Applying the ABC model theory of attitude, in this study, I will arrange the findings on the change of social attitudes towards LGBT in VN, according to each component group of the model so that readers can see the problem more clearly and systematically. This does not mean that I predefine SATL categories based on ABC theory as instructed in content analysis (Bauer \& Gaskell, 2000), but these are just very general aspects of attitude for me to organize the themes originated from data.

Data analysis is based on grounded theory (GT). Since the influential work of Strauss and Corbin (1998), grounded theory has developed and become the fundamental and integrative engine in functioning a qualitative research. GT includes a spiral of data collection, coding, analysis, writing, design, theoretical categorization. It suggests a continuous comparison of data and theory, in other word theoretical and practical categories to see what is available and what is novel to scholarship.

\section{FINDINGS AND DISCUSSIONS}

The causes of SATL change in Vietnam: Interplay between social, political processes and media

In a review of Adamczyk and Liao (2019) regarding SATL across multiple countries published in the Annual review of sociology, they divide factors influencing attitudes into individuallevel and country-level groups. For the micro-level, they mention gender, education, marital status, age, religious values, races, ethnicity, and the macro-level includes economic development, political history, democracy orientation, media, national religion, being a British colony and the LGBT movement. There is no doubt that they all shape each individual's 
attitudes regarding homosexuality, which is a useful reference for related research. However, in this research, I am not trying to investigate the connections of all those factors with individual attitudes at a specific point of time. Rather, I am spending my best efforts to point out the major factors that trigger the change of Vietnamese social attitudes at the country level throughout the last ten years or more. From the data analysis, I conclude the three significant forces as follows.

\section{Social activism}

The establishment and activities of civil society organizations fighting for LGBT rights have had a great impact on politics, law, society and media in Vietnam (Oosterhoff et al., 2014). The most active centers are ISEE, ICS headed by young people with expertise and the ability to connect individuals, organizations and society. These organizations have organized mild campaigns politically and socially and connect with individuals and organizations in Vietnam and abroad to lobby the Vietnamese government and parliament to introduce laws for LGBT rights, such as the legalization of same-sex marriage, the anti-discrimination law against LGBT people. On the social side, these organizations organize and co-organize annual Viet Pride parades in many provinces across the countries, imposing an enormous impact on LGBT representation in society and media. They also work directly with media in Vietnam to inform sexual knowledge and LGBT rights advocacy process through interviews, conversations and exchanges with domestic and foreign media. They also organize training courses for voluntary social activists to deliver positive LGBT messages to companies, schools and work with government organizations and NGOs for social and political purposes. Although these civil society groups do recognize certain advances for LGBT rights in Vietnam, their activities generally focus on the widespread existence of heteronormativity, discrimination, inequality in their seminars, research, reports or interviews with domestic and international media. In 
short, civil society organizations' role is one of the keys to bringing LGBT issues and their rights to a higher equality level.

\section{Political-legal change:}

The 2000 Law on Family and Marriage in Vietnam prohibits same-sex marriage. However, many same-sex couples in Vietnam still choose co-habitation or organize their weddings. A gay couple in Ha Tien province in 2012 held a wedding but was banned by the local authorities. This caused a stir in public opinion on the law and same-sex marriage in Vietnam. At the same time, civil society organizations on LGBT rights are working actively. With such changes in the current social situation in Vietnam, in 2012, the Ministry of Justice proposed allowing same-sex marriage with the participation of LGBT activists as advisers. Although same-sex marriage has not been recognized, it was no longer banned after parliament passed a bill on June 14, 2014, which came into effect on January 1, 2015. In this bill, same-sex marriage is allowed but not recognized and protected by law. Despite its limitations, this change was considered a big step forward for an Asian country like Vietnam at that time. Jamie Gillen (2015), a researcher on Southeast Asia and Vietnam at the University of Auckland, stated that Vietnam had made a big step forward in terms of social and human rights while the more developed countries in the region are still conservative about homosexuality ${ }^{1}$.

Civil society organizations together with LGBT rights activists in Vietnam have little satisfaction with the political and legal improvements in Vietnam for LGBT. They believe that the government's improvements are still minimal compared with developed countries and with the equal rights that LGBT people deserve, such as anti-discrimination and same-sex marriage. In their studies, reports as well as in findings from some other researchers, the cause of these

\footnotetext{
${ }^{1}$ https://www.metroweekly.com/2015/01/vietnam-removes-same-sex-marriage-ban/
} 
shortcomings is attributed to the long-standing social and cultural norms in Vietnam on the heteronormative regime of love, marriage and family (Horton, 2019; Oosterhoff et al., 2014). Yes, the process of legalizing LGBT rights might not proceed as expected by the LGBT community and by civil society organizations, but at least, with an attitude of "not admitting but not banning," new doors are opened for society and media to discuss more lively about LGBT issues.

\section{Media}

In the past five years, images and stories of LGBT have increasingly appeared in more quantity and quality in mass media in Vietnam, mainly in television, cinema, newspaper, and social media. On Vietnam's most prominent television stations, such as VTV, HTV, we can see the image of LGBT people presented more frequently on programs o various genres such as news, movies, game shows, talk shows. In the multi-season movie about the Vietnamese police, "Cảnh sát hình sự" (Criminal police) aired on VTV, in 2003 there were ten episodes in the series titled "Một thế giới không có đàn bà" (A world without women) adapted from a samename novel by novelist Bui Anh Tan. The plot revolves around two main characters who have a same-sex relationship. Although the film has a heteronormative ending, the view on LGBT and the happy ending when it was released in the early 2000s also showed the humanistic perspective on homosexuality in Vietnam at that time. In recent years, an explosion of LGBT representation on media can be seen on television game shows like "Người Ấy là ai" (Who is who), "Người bí ẩn" (Mystery person) on HTV, hit cinema movies like "Song Lang" (Male couples)," Về nhà đi con" (Go home, son!), talk shows like "Đối thoại chính sách "(Policy dialogue)," Chuyện cuối tuần" (Weekend stories) on VTV, music videos with more than tens of million YouTube views like "Hơn cả yêu" (More than love) by singer Duc Phuc," Có như không có" (Have like do not have) by singer Hien Ho," Tặng anh cho cô ấy" (I give her to you) 
by Huong Giang idol. Besides, the popularity of the Internet and social media also creates opportunities for many private organizations and individuals to produce programs related to the LGBT community. Most notably, MCV media group with specialized LGBT programs on YouTube has received a strong social response through views (from hundred thousand to millions view on each video), subscriptions (more than 5 million subscribers totally in MCV media, MCV TV, LOVE TV channels) and variety of newspaper coverage. In particular, the most famous programs such as "Come out - BRAS", "Real life", "Mẹ chồng chàng dâu" (Mother-in-law of the bride), "Yêu là cưới" (Love and marriage) have conveyed a huge amount of information about life and experiences of LGBT people from diverse social sectors, including famous people (singer Lam Khanh Chi, singer Lynk Lee) and successful people in society. In addition, there is another prominent traditional lottery show named "Lô tô" by "Sài Gòn Tân Thời” troupe (Modern Saigon troupe), which appeared on their own YouTube channel and major TV stations such as THVL, HTV. To preserve a traditional Vietnamese lottery and bring entertainment to the community, they have conveyed a positive image of LGBT people as talented actors and singers in the show. When referring to showbiz industry, I cannot help mentioning that many famous singers, actors, models, and MCs in Vietnam have revealed their homosexual stories. Surprisingly, they received a welcome, support, and respect. Three top Vietnamese singers are transgender (Lam Khanh Chi, Huong Giang, Lynk Lee), while Huynh Lap and BB Tran are widely mentioned names of famous gay actors. The samesex love of MC Ngoc Trang (VTV) also costs substantial media coverage, which mainly praises this couple's talent, beauty, and love.

There is also a wealth of textual, visual, and audio information generated by individuals using social networks, mainly YouTube and Facebook. Currently, the most popular Facebook group for Vietnamese LGBT community is "Gay $18+$ confession" with nearly 200k followers and more than 40,000 posts about romance, family, coming out, relationships and careers of LGBT 
people and their friends, family, colleagues who have interest in LGBT topic. Many YouTube channels of individuals including celebrities have posted a lot of information delivering images, views, experiences, attitudes and feelings related to the LGBT community. Most recently, a Web drama "Mẹ mẹ con con" (Mother and Child) revolves around four main gay and lesbian characters produced and released in early 2021 by "Hồng Vân entertainment" channel owned by People's Artist Hong Van. The story ends happily with the fact that couples overcame family and social barriers to reach each other with support from everyone. It is worth noting that the People's artist (the noblest title in the art field from the Vietnamese government) is a veteran Vietnamese speech theater artist, and she is not a member of the LGBT community. Her switch to investing in LGBT-related content is one of the countless manifestations of media's interest in LGBT issues in Vietnam.

In short, media with its function of reflection and impact (Calzo \& Ward, 2009; G. Lewis \& Gossett, 2008) has shown dramatic and positive changes in the image of LGBT people and has influenced authorities and people's attitudes regarding the LGBT issue in Vietnam. I do not deny the negative sides regarding discrimination, family difficulties as well as stories about jealousy, prostitution, MSM and SDTs in the LGBT community conveyed through media in Vietnam. But they are told with the point that remaining issues need to be handled to ensure fairness and humanity for people of all sectors. They should not be equated to characterize the entire LGBT community. As can be seen, for the past five years, media play a crucial role in expressing an increasingly positive image of the LGBT community and have the most substantial impact on awareness, opinion and attitudes of Vietnamese society towards LGBT issues. Up to now, there has hardly been any research on the drastic change of LGBT media in Vietnam other than some studies that are not updated regarding the contemporary LGBT situation in Vietnam. (Nguyen, 2020; Oosterhoff et al., 2014). 
From all the above analysis, it is clear that three factors of social activism, legal change and media interact strongly, positively influence social attitudes towards LGBT in Vietnam. These findings are consistent with other research on factors influencing SATL change in other Western contexts (Ayoub \& Garretson, 2016). However, these factors may have different roles and impacts in different contexts (Adamczyk \& Liao, 2019). The above analysis has also clearly shown the role and sequence of those factors in Vietnam over the past decade. Social activism triggered the movement fighting for equal rights for the LGBT community in the late 2000s and continues to operate until today. This struggle paved the way for the more openness of political and legal situation (through the abolition of the law prohibiting same-sex marriage in 2014) and has attracted ample attention from the media. In recent years, with such strides towards the gay rights movement in Vietnam and around the world, public and private media in Vietnam have the opportunity to exploit more deeply and specifically about LGBT with a humane approach. It plays a key role in expressing positive LGBT images and influencing social attitudes. The next section will discuss and analyze the characteristics, nature and direction of SATL change in Vietnam over the past decade.

\section{More open society for LGBT community in terms of affection, behavior and cognition.}

I have made arguments about the causes of changing Vietnamese social attitudes towards LGBT issues, in which I mentioned somewhat the positive trend of change in this form of social consciousness, especially in the discussion on media. In this section, I will present practical data that both serve as more concrete evidence of changes in social attitudes (in terms of ideas) and as a source of materials for in-depth analysis and discussion on the characteristics and direction of this process. The data sources here are from both domestic and foreign media regarding the social progress of the LGBT issue in Vietnam so that we can see the objectivity of the problem. 
In some recent programs of ANTV, an official television channel of the Vietnamese police force, some issues related to same-sex love and attitudes of family and society have been carried out under many forms such as hypothetical situations, interviews, talk shows ... It is worth noting that an official TV channel of the Vietnamese defense and security forces exploits LGBT theme with a radical, humanistic approach that promotes social understanding and empathy for this community. These programs are also uploaded to YouTube on the channel "ANTV -Truyền hình Công An nhân dân" (people's police television) to get closer to nationwide audiences. In addition to common information and stories about obstacles in the life of the LGBT community, such as disclosure to families, and social stigma, there are surprisingly positive lights of all three aspects of attitude (affect, behavior, cognition).

In 2019, this media channel had two video clips in the program "Kỹ năng sống” (Life skills) to create a hypothetical situation to consider social attitudes towards same-sex relations in Vietnam. In the program No. 59 released on April 2, $2019^{2}$, "Bạn sẽ làm gì khi thấy người đồng tính bị kì thị quá đáng?" (What will you do when you see that homosexuals are stigmatized excessively?), the producer built up a hypothetical situation of homosexual couples subjected to a group of young people stigmatizing them in order to investigate the reaction of the surrounding people. All participants in this situation are amateur actors and were filmed by secret cameras to ensure the program's objectivity. As a result, the homosexual couples were protected by the people around them while the weirdos were criticized and dismissed. Obviously, this is a very positive sign reflecting support for LGBT people and opposition to homosexual stigma and discrimination. For further understandings, the program interviewed people who witnessed or reacted towards the situation. A lady in her U40s, a resident of Hanoi,

\footnotetext{
${ }^{2}$ https://www.youtube.com/watch?v=ixqnhefJYYY
} 
directly discouraged the youth group's stigmatization and helped the gay couple to avoid that incident. This lady shares as follows:

"When I saw them behave excessively, I discourage and advise them on respect for the privacy of others regardless of gender, sexual orientation ... LGBT needs to be treated equally with love".

Another young girl in her 20s also shared the following radical anti-discrimination:

“... I think nowadays, people's way of thinking about "the third world" (the gay community), about homosexuality is also very normal, nothing to be criticized. People with discrimination towards LGBT are unwise, immoral and deserve to be condemned".

At the end of the video, the program gave anti-discrimination recommendations for the community and advice for LGBT people if they encountered stigma. These messages clearly represent the protection of a Vietnamese state mouthpiece for the LGBT community. In addition, also in this "Kỹ năng sống" (life skills) program, No. 12, the producer also made a video about homosexuality, family and community premiered on January $21,2019^{3}$. In this video, the producer created two situations in which LGBT couples were opposed by their parents and observed the reactions of people around them, then interviewed further about their opinions. Similar results appeared in this video clip. A teenage girl interferes with a quarrel by a gay couple and one's mother in the street; she shares with the mother: "Auntie, your child is 18 years old, so he has his citizenship and rights... I think now all men, girls, LGBT have equal rights". Two elderly people sitting nearby when being interviewed also expressed a positive opinion: "Now that is normal, many people are like that, many countries around the world also allow same-sex marriage."

\footnotetext{
${ }^{3}$ https://www.youtube.com/watch?v=vPY1YCW0kJc\&t=841s
} 
In general, through 2 videos of ANTV surveying social attitudes towards homosexuality, we can clearly see the movement towards more openness. The phrase "Bây giờ xã hội đã cởi mở hon rồi" (nowadays, society is more open to LGBT) continuously expressed in the two videos are a testament to this, following to the global trend (Smith et al., 2014). From the analysis of data, this openness is manifested in three aspects in the $\mathrm{ABC}$ model of attitude. In findings, affection includes empathy, love, respect, even fanaticism, admiration. Behavior involves protecting, supporting, favoring. Cognition shows in terms of human rights and law. Next is the detail of each aspect. First involves the perception of law, human rights. Participants from different ages and social backgrounds all mentioned the rights for freedom, equality regardless of sexual orientation. Obviously, this is the result of positive changes in the world and in Vietnam in terms of the human rights legalization process. This finding is contrary to that of Do et al. (2019), demonstrating the indifference and avoidance of Vietnamese society towards LGBT rights. The second aspect of changing attitudes is related to the act of protecting homosexuals against stigmatization. In the program above, stigma is just an experiment to test social response. In fact, in contemporary Vietnam, if someone wants to discriminate against LGBT, it is not easy because public opinion will protect LGBT people. This finding challenges studies claiming that stigma and discrimination are still widespread in Vietnam, especially in rural areas (UNDP \& USAID 2014; Do et al. 2019; Luong \& Pham 2015). I am skeptical of the view that rural areas or the elderly lack understanding of LGBT, leading to stigma (Luong \& Pham 2015; Becker 2012). Internet and media do not distinguish between urban or rural areas, old or young, so anyone who has access to these information sources hardly lacks updates on LGBT-related knowledge and situation in the world and Vietnam. I mentioned people from young to old age groups in the data above. Later data will express opinions representing the countryside. 
Countless similar examples will show up when we search "Cặp đôi đồng tính" (gay couple), "Kết hôn đồng giới” (gay marriage) on YouTube or Google. Findings also show empathy, love, even fanaticism of same-sex love and admiration for the talents of LGBT. On social networking sites, many social groups are fans of LGBT couples such as "Đam mỹ - Hủ nữ/ hủ nam muôn năm”, “Đam Mỹ - Damei” (Yaoi fan groups). These findings depict the process of homosexual normalization expressed in both emotion and behavior. A veteran supermodel of the Vietnamese showbiz had an introductory phrase in a talk show about transgender people: "We see a great social interest in the LGBT community expressed through media, social media" ${ }^{4}$. In an MVC talk show broadcast on YouTube channel LOVETV with nearly 2 million views and more, MC Quyen Linh (a famous MC, an actor in Vietnam, and not a member of the LGBT community) interviewed a gay couple about their life:

MC Quyen Linh: Now it's very comfortable for me to talk about these things (Homosexuality), not as difficult as 5-10 years ago ... Now there is no more discrimination ... You are so cute and talented that I also feel like you.

Gay couple: I live in the countryside, not in the urban area, so the media was very little in the past, and people still stigmatized LGBT a lot. But now, I see that things get better. Sometimes, I find them appreciate us a lot more. When people buy our products to support us, we clearly see their love and care for us. $^{5}$

In hypothesized situations on ANTV, there are only two expressions that may cause some people to think in a negative way about SATL in Vietnam. The first is a mother who does not accept her daughter's relationship with a same-sex lover (fake lover). In my opinion, this mother's response was very humane and understandable. She is very polite in showing

\footnotetext{
${ }^{4}$ https://www.youtube.com/watch?v=ktTsJrqBH_Q

${ }^{5}$ https://www.youtube.com/watch?v=QLIiU6 Nq6U
} 
disapproval, and of course, it is difficult to accept because her daughter has not shown any signs of homosexuality. Another act of an auntie over 50, when seeing a mother forbid samesex love of her son, has come to advise them to go home for calm discussion and recommend other people not to interfere with the family issue. This comes from empathy for the mother's anxiety when she suddenly found out that her son is gay. The above stories may partly show parents' heteronormativity towards their children but not the stigmatizing attitudes towards LGBT in general. The parent-child relationship has a lot to do with the values of love, marriage, family, and children that are beyond the limits of this study on general social attitudes towards LGBT in Vietnam.

Indeed, these findings in an Asian socialist country with heavy Confucian ideology and heteronormativity, without specific laws protecting LGBT, are valuable as they show both consistent and inconsistent findings with other research (Adamczyk \& Cheng, 2015; Adamczyk \& Liao, 2019; Smith et al., 2014).

\section{The normalization of homosexuality versus heteronormativity:}

With all the above data and analysis, we can see the emergence of homosexual normalization in Vietnam. Particularly, the repetitive saying "Bây giờ chuyện đó bình thường/phổ biến rồi” (it is normal/common now) is a testament to the fact that the view of heteronormative domination in Vietnamese society is strongly challenged. Another example, a talk show on the VTV9 TV channel called "Chuyện cuối tuần” (weekend story) also held a conversation with a famous Miss Businesswoman Thu Hoai on the topic of "Khi con đồng tính" (when your child is gay). The reason she was invited is not only about her social influence but also due to her son being gay. She and her son often appear on many talk shows to share their positive stories. 
During the talk show, change in social attitudes was clearly identified and given by both Thu Hoai and MC Le Hoang (a famous Arts director in Vietnam) as follows:

MC Le Hoang: Recently, in the world, many countries are supporting and protecting the rights of LGBT people. Nowadays, a knowledgeable person will realize that it is not important now to judge a person by sexual orientation but their contribution to society. In fact, I realized that LGBT people seem to be usually talented. ${ }^{6}$

I do not deny that injustice, stigma, and heterosexualism still exist in parts of the Vietnamese society at various levels, such as opinions from many LGBT rights activists and researchers. In an article by HuffPost titled "Vietnam has been praised as a leader in LGBT rights. Activists beg to differ", the author has cited some opinions from a number of major media about LGBT rights in Vietnam, for example, "Vietnam: Flawed on Human Rights, but a Leader in Gay Rights" on Atlantic (2013), "On gay rights, Vietnam is now more progressive than America" on NBC News. However, when they interviewed Luong The Huy, director of Vietnam's Institute for Studies of Society, Economy and Environment (ISEE), he said, "Because of traditional norms - such as keeping the family line intact, saving face, etc. - there is a lot of stigma and misunderstanding... Many people also think that LGBT people are' social evils, 'or that it is 'fashion' or 'social trend.'... most LGBT people still hide their sexuality from their parents". Those activists are talented, young, dedicated and have many contributions to the LGBT movement in Vietnam, but they still embrace an inherent orientation among LGBT activists around the world, considering LGBT as a vulnerable small group still facing injustices and discrimination, which will unintentionally put LGBT at a disadvantage in terms of social

\footnotetext{
${ }^{6}$ https://www.youtube.com/watch?v=7OWYOP5AEhk\&t=1131s
} 
status. Ward (2008) also raised this point of view when she argued that LGBT organizations, with the aim of protecting disadvantaged minor groups, accidentally create neoliberal identity politics and the institutional exclusion of minorities. This is understandable because discrimination and injustice are the roots of their activities. Some researchers also have a similar viewpoint when claiming that heteronormativity has been operating overwhelmingly in Vietnamese society and politics of love, marriage, family (Horton, 2019; Newton, 2015; Oosterhoff et al., 2014). I partially agree with this opinion. On the other hand, we have to recognize new ideas that have just been presented in Vietnamese society, expressing a remarkable change in contemporary Vietnamese society within the context of globalization, industry 4.0. Pullen \& Cooper (2010) coin the term "LGBT transnational identity" in order to point out the widespread and diverse LGBT culture worldwide but Vietnam was not mentioned in their work while LGBT issues here have changed dramatically in the last decade. In fact, the normalization of homosexuality in Western societies has been mentioned so far (Bech, 1999; Roseneil et al., 2013; Weeks et al., 2018), which is connected with the legalization of LGBT rights equal to the other dominant group. However, this research points out that even though the legal process is still limited in Vietnam, the normalization of homosexuality has been emerging considerably in Vietnamese society. Any opinion that underestimates the progressive change in SATL in Vietnam is lacking in consideration. Rather, in the process of social attitudes change, new values are born, both cooperating and fighting with old concepts to gradually form a combination of values appropriate to a specific time. It is the law of unity and struggle between opposites (Engels et al., 1940) developed upon classic Hegelian dialectic model of change indicating the interaction of opposing forces.

\section{CONCLUSION}

From the above analysis, we can see the cause, direction and characteristics of SATL in Vietnam. With the resonance of social activism, politics and media, this process has emerged 
with new, more human, more equal values (normalization of homosexuality) in addition to the remaining influence of heteronormativity. Researchers and social activists should have an objective and multidimensional view of changing SATL in Vietnam to have more significant impacts. This change then becomes a new basis for the political and social advocacy process for the LGBT community.

In this study, using secondary data, I can only study the general trend of social attitudes towards LGBT in Vietnam. Of course, in each person, each sub-culture, each social class, apart from the common features of SATL, there can be distinct features. Therefore, there is still a substantial demand for research regarding demographic differences/similarities (age, marital status, education, nationality, religion, and ethnicity) or social sub-contexts such as schools, state agencies, security and defense forces (Brown \& Henriquez, 2008). Other studies may then collect more specific and primary data from interviews or surveys.

Although SATL studies have been done with global surveys (e.g., World values survey), there are still many features that we would not have realized without a thorough study of each context, as the case of homosexual normalization in this research. And the specific characteristics of each context will clarify the universal arguments on heteronormativity and normalization of homosexuality. These efforts are valuable for forecasting future trends of SATL and for research or public policy.

\section{REFERENCES}

Adamczyk, A. (2017). Cross-National Public Opinion about Homosexuality Examining Attitudes across the Globe (1 ed.). University of California Press. http://www.jstor.org/stable/10.1525/j.ctt1jd947w

Adamczyk, A., \& Cheng, Y.-h. A. (2015, 2015/05/01/). Explaining attitudes about homosexuality in Confucian and non-Confucian nations: Is there a 'cultural' influence? Social Science Research, 276-289. https://doi.org/https://doi.org/10.1016/j.ssresearch.2014.10.002 
Adamczyk, A., \& Liao, Y.-C. (2019). Examining public opinion about LGBTQ-related issues in the United States and across multiple nations. Annual Review of Sociology, 45, 401423.

Akker, H., Ploeg, R., \& Scheepers, P. (2012, 02/27). Disapproval of Homosexuality: Comparative Research on Individual and National Determinants of Disapproval of Homosexuality in 20 European Countries. International Journal of Public Opinion Research, 25, 64-86. https://doi.org/10.1093/ijpor/edr058

Andersen, R., \& Fetner, T. (2008). Economic Inequality and Intolerance: Attitudes toward Homosexuality in 35 Democracies. American Journal of Political Science, 52(4), 942958. https://doi.org/https://doi.org/10.1111/j.1540-5907.2008.00352.x

Ayoub, P. M., \& Garretson, J. (2016, 2017/07/01). Getting the Message Out: Media Context and Global Changes in Attitudes Toward Homosexuality. Comparative Political Studies, 50(8), 1055-1085. https://doi.org/10.1177/0010414016666836

Bauer, M., \& Gaskell, G. (2000, 01/01). Qualitative Researching with Text, Image and Sound: A Practical Handbook for Social Research.

Bech, H. (1999, 1999/08/01). Commentaries on Seidman, Meeks and Traschen: 'Beyond the Closet?': After the Closet. Sexualities, 2(3), 343-346. https://doi.org/10.1177/136346099002003006

Breckler, S. J. (1984). Empirical validation of affect, behavior, and cognition as distinct components of attitude. Journal of Personality and Social Psychology, 47(6), 11911205. https://doi.org/10.1037/0022-3514.47.6.1191

Brown, M. J., \& Henriquez, E. (2008). Socio-demographic predictors of attitudes towards gays and lesbians. Individual Differences Research, 6(3), 193-202.

CNN. (2019). LGBTQ Rights Milestones Fast Facts. https://edition.cnn.com/2015/06/19/us/lgbt-rights-milestones-fast-facts/index.html

Do, Q. A., Chu, L. A., D., D. Q., Vuong, K. P., \& Nguyen, B. N. (2019). Báo cáo nghiên cúu: quan điểm xã hội về hôn nhân đồng giới ở VIệt Nam [Research report: social attitude towards same-sex marriage in Vietnam].

Flores, A. R. (2015). Examining Variation in Surveying Attitudes on Same-Sex Marriage: A Meta-Analysis. Public Opinion Quarterly, 79(2), 580-593. https://doi.org/10.1093/poq/nfv017

Gould, J. A., \& Moe, E. (2015, 2015/09/03). Nationalism and the Struggle for LGBTQ Rights in Serbia, 1991-2014. Problems of Post-Communism, 62(5), 273-286. https://doi.org/10.1080/10758216.2015.1041840

Hadler, M. (2012). The influence of world societal forces on social tolerance. A time comparative study of prejudices in 32 countries. The Sociological Quarterly, 53(2), 211-237. https://doi.org/https://doi.org/10.1111/j.1533-8525.2012.01232.x 
Hodal, K. (2020). Vietnam accused of teaching young people that being gay is a 'disease'. The Guardian. https://www.theguardian.com/global-development/2020/feb/13/vietnamaccused-of-teaching-young-people-that-being-gay-is-a-disease

Horton, P. (2019). Recognising shadows: masculinism, resistance, and recognition in Vietnam. NORMA, 14(1), 66-80. https://doi.org/10.1080/18902138.2019.1565166

Hutt, R. (2018). This is the state of LGBTI rights around the world in 2018. Weforum.

Inglehart, R., \& Welzel, C. (2005). Modernization, Cultural Change, and Democracy: The Human Development Sequence. Cambridge: Cambridge University Press. https://doi.org/doi:10.1017/CBO9780511790881

Lewis, G. B., \& Gossett, C. W. (2008). Changing Public Opinion on Same-Sex Marriage: The Case of California. Politics \& Policy, 36(1), 4-30. https://doi.org/https://doi.org/10.1111/j.1747-1346.2007.00092.x

Lewis, S. (2016). Same-Sex Marriage Ban Lifted in Vietnam But a Year Later Discrimination Remains. Time. https://time.com/4184240/same-sex-gay-lgbt-marriage-ban-liftedvietnam/

Luong, H., \& Pham, P. (2015). Is it because I am LGBT?: Discriminations on Sexual Orientation and Gender Identity in Vietnam.

Maresca, T. (2013). Vietnam: Flawed on Human Rights, but a Leader in Gay Rights. The Atlantic. https://www.theatlantic.com/international/archive/2013/04/vietnam-flawedon-human-rights-but-a-leader-in-gay-rights/275413/.

Mosbergen, D. (2015). Vietnam Has Been Praised As A Leader In LGBT Rights. Activists Beg To Differ. Huffpost. https://www.huffpost.com/entry/lgbtvietnam_n_56163a78e4b0e66ad4c68090.

Newton, N. (2014). Homosexuality and transgenderism in Vietnam. In M. McLelland \& V. Mackie (Eds.), Routledge Handbook of Sexuality Studies in East Asia (1 ed., pp. 255267). Routledge. https://doi.org/https://doi.org/10.4324/9781315774879

Nguyen, T. (2020). The Fight for LGBT Rights in Vietnam Still Has a Long Way To Go. The Diplomat. https://thediplomat.com/2020/02/the-fight-for-lgbt-rights-in-vietnam-stillhas-a-long-way-to-go/

Oosterhoff, P., Hoang, T. A., \& Quach, T. T. N. (2014). Negotiating public and legal spaces: the emergence of an LGBT movement in Vietnam.

Perloff, R. M. (2017). The dynamics of persuasion: Communication and attitudes in the 21st century. https://doi.org/10.4324/9781315657714

Pullen, C., \& Cooper, M. (2010). LGBT Identity and Online New Media (First ed.). Routledge. https://doi.org/https://doi.org/10.4324/9780203855430 
Rhoades, M. (2011). Disrupting Discourses Digitally for LGBTQ Rights. Journal of Cultural Research in Art Education, 29, 47-64.

Roseneil, S., Crowhurst, I., Hellesund, T., Santos, A. C., \& Stoilova, M. (2013). Changing Landscapes of Heteronormativity: The Regulation and Normalization of Same-Sex Sexualities in Europe. Social Politics: International Studies in Gender, State \& Society, 20(2), 165-199. https://doi.org/10.1093/sp/jxt006

Scheepers, P., Grotenhuis, M. T., \& Van Der Slik, F. (2002). Education, Religiosity and Moral Attitudes: Explaining Cross-National Effect Differences. Sociology of Religion, 63(2), 157-176. https://doi.org/10.2307/3712563

Sender, K. (2006, 2006/06/01). Queens for a Day: Queer Eye for the Straight Guy and the Neoliberal Project. Critical Studies in Media Communication, 23(2), 131-151. https://doi.org/10.1080/07393180600714505

Smith, T., Son, J., \& Kim., J. (2014). Public Attitudes Towards Homosexuality and Gay Rights Across Time and Countries. https://williamsinstitute.law.ucla.edu/publications/publicattitudes-intl-gay-rights/

Strauss, A., \& Corbin, J. (1998). Basics of qualitative research: Techniques and procedures for developing grounded theory, 2nd ed. Sage Publications, Inc.

UNDP, \& USAID. (2014). Being LGBT in Asia: Viet Nam Country Report.

Ward, J. (2008). Respectably queer: Diversity culture in LGBT activist organizations. Vanderbilt University Press.

Weeks, A., Altman, D., Stevens, A., Lorthridge, J., \& Heaton, L. (2018). Strengthening the Workforce to Support Youth in Foster Care who Identify as LGBTQ+ through Increasing LGBTQ+ Competency: Trainers' Experience with Bias. Child Welfare, 96(2), 125-150.

Winn, P. (2015). On gay rights, Vietnam is now more progressive than much of the US. Nbcnews. https://www.pri.org/stories/2015-01-13/gay-rights-vietnam-now-moreprogressive-much-us

Zheng, T. (2015). Tongzhi Living: Men Attracted to Men in Postsocialist China. University of Minnesota Press. http://www.jstor.org/stable/10.5749/j.ctt173zm6h 